\title{
Correction to: Total thyroidectomy with therapeutic level II-IV neck dissection for papillary thyroid carcinoma: level VI recurrence patterns
}

Narin N. Carmel-Neiderman ${ }^{1}$ (1) Irit Duek ${ }^{1}$ - Dana Amsterdam ${ }^{1} \cdot$ Anat Wengier $^{1}$ - Boris Kuzmenko ${ }^{1}$ - Barak Ringel ${ }^{1}$. Anton Warshavsky ${ }^{1} \cdot$ Udi Shapira $^{1} \cdot$ Gilad Horowitz ${ }^{1} \cdot$ Elena Izkhakov $^{2} \cdot$ Dan M. Fliss $^{1}$

Published online: 13 August 2020

(c) Springer-Verlag GmbH Germany, part of Springer Nature 2020

\section{Correction to: European Archives of Oto-Rhino-Laryngology \\ https://doi.org/10.1007/s00405-020-06079-4}

In the original publication of the article, one of the author name was published incorrectly as "Gilad Horovitz". The correct name is "Gilad Horowitz".

The original article was corrected.

Publisher's Note Springer Nature remains neutral with regard to jurisdictional claims in published maps and institutional affiliations.

Dan M. Fliss

danf@tlvmc.gov.il

1 Department of Otolaryngology, Head and Neck and Maxillofacial Surgery, The Interdisciplinary Center for Head and Neck Surgical Oncology, Tel-Aviv Sourasky Medical Center, 6 Weitzman Street, 6423906 Tel-Aviv, Israel

2 Endocrinology Unit, Tel Aviv Sourasky Medical Center, affiliated to the Sackler Faculty of Medicine, Tel Aviv University, Tel Aviv, Israel 